\title{
Fetal Male Gender and the Benefits of Treatment of Mild Gestational Diabetes
}

\author{
Ray O. BAHADO-SINGH, M.D., MBA ${ }^{1}$, Lisa MELE, Sc.M. ${ }^{2}$, Mark B. LANDON, M.D. ${ }^{3}$, Susan \\ M. RAMIN, M.D. ${ }^{4}$, Marshall W. CARPENTER, M.D. ${ }^{5}$, Brian CASEY, M.D. ${ }^{6}$, Ronald J. \\ WAPNER, M.D. ${ }^{7}$, Michael W. VARNER, M.D. ${ }^{8}$, Dwight J. ROUSE, M.D. ${ }^{9}$, John M. THORP Jr., \\ M.D. ${ }^{10}$, Anthony SCISCIONE, D.O. ${ }^{11}$, Patrick CATALANO, M.D. ${ }^{12}$, Margaret HARPER, M.D., \\ M.Sc. ${ }^{13}$, George SAADE, M.D. ${ }^{14}$, Steve N. CARITIS, M.D. ${ }^{15}$, Alan M. PEACEMAN, M.D. ${ }^{16}$, and \\ Jorge E. TOLOSA, M.D., M.S.C.E ${ }^{17}$ for the Eunice Kennedy Shriver National Institute of \\ Child Health and Human Development Maternal-Fetal Medicine Units Network \\ ${ }^{1}$ Division of Maternal-Fetal Medicine, Department of Obstetrics and Gynecology, Hutzel Women's \\ Hospital, Detroit, MI \\ ${ }^{2}$ The George Washington University Biostatistics Center, Washington, DC \\ ${ }^{3}$ Department of Obstetrics and Gynecology of The Ohio State University, Columbus, $\mathrm{OH}$ \\ ${ }^{4}$ The University of Texas Health Science Center at Houston, Houston, TX \\ ${ }^{5}$ Brown University, Providence, RI \\ ${ }^{6}$ University of Texas Southwestern Medical Center, Dallas, TX \\ ${ }^{7}$ Columbia University, New York, NY \\ ${ }^{8}$ University of Utah, Salt Lake City, UT \\ 9University of Alabama at Birmingham, Birmingham, AL \\ 10University of North Carolina at Chapel Hill, Chapel Hill, NC \\ ${ }^{11}$ Drexel University, Philadelphia, PA \\ ${ }^{12}$ Case Western Reserve University-MetroHealth Medical Center, Cleveland, $\mathrm{OH}$ \\ ${ }^{13}$ Wake Forest University Health Sciences, Winston-Salem, NC \\ ${ }^{14}$ University of Texas Medical Branch, Galveston, TX \\ ${ }^{15}$ University of Pittsburgh, Pittsburgh, PA \\ ${ }^{16}$ Northwestern University, Chicago, IL
}

\footnotetext{
C 2012 Published by Mosby, Inc.

Corresponding Author: Ray O. Bahado-Singh MD, MBA, Hutzel Women's Hospital, 3990 John R., Mailbox \#167, Detroit, MI 48201, Business telephone: 313-993-1379, Home telephone: 313-729-4062, Fax number: 313-993-4438, rbahados@ med.wayne.edu. DISCLOSURE: None of the authors have a conflict of interest.

Publisher's Disclaimer: This is a PDF file of an unedited manuscript that has been accepted for publication. As a service to our customers we are providing this early version of the manuscript. The manuscript will undergo copyediting, typesetting, and review of the resulting proof before it is published in its final citable form. Please note that during the production process errors may be discovered which could affect the content, and all legal disclaimers that apply to the journal pertain.
} 
${ }^{17}$ Oregon Health \& Science University, Portland, OR

\section{Abstract}

Objective-We evaluated whether improvements in pregnancy outcomes after treatment of mild GDM differed in magnitude based on fetal gender.

Methods-This is a secondary analysis of a masked RCT of treatment for mild GDM. Outcomes included preeclampsia or gestational hypertension, birth weight, neonatal fat mass, and composite adverse outcomes for both neonate (preterm birth, SGA or NICU admission) and mother (labor induction, cesarean delivery, preeclampsia or gestational hypertension). After stratification according to fetal gender, the interaction of gender with treatment status was estimated for these outcomes.

Results-Of 469 pregnancies with male fetuses, 244 were randomized to treatment and 225 to routine care. For those with female fetuses, these numbers were 463, 233 and 230 respectively. The interaction of gender with treatment status was significant for fat mass $(\mathrm{p}=0.04)$ and birthweight centile $(\mathrm{p}=0.02)$. Among women who were assigned to the treatment group, male offspring were significantly more likely to have both a lower birth weight centile $(50.7 \pm 29.2 \mathrm{vs}$ $62.5 \pm 30.2$ centile, $\mathrm{p}<0.0001)$ and less neonatal fat mass ( $487 \pm 229.6$ vs. $416.6 \pm 172.8 \mathrm{~g}, \mathrm{p}=$ $0.0005)$ whereas these differences were not significant among female offspring. There was no interaction between fetal gender and treatment group with regard to other outcomes.

Conclusion-The magnitude of the reduction of a newborn's birth weight centile and neonatal fat mass related to the treatment of mild GDM appears greater for male neonates.

\section{Keywords}

gender; gestational diabetes mellitus; pregnancy outcomes

\section{Introduction}

Two recent randomized studies reported that therapy of mild gestational diabetes mellitus (GDM) results in a reduction of birth weight. ${ }^{1,2}$ In one of these studies, performed by the NICHD Maternal Fetal Medicine Unit (MFMU) Network, ${ }^{2}$ we also reported a significant reduction in neonatal fat mass in the treatment versus the standard clinical care group.

GDM is characterized by increased oxidative stress (OS) in both maternal blood and placental tissues. ${ }^{3}$ Recent laboratory studies of hepatic cells in culture demonstrated that $\mathrm{H}_{2} \mathrm{O}_{2}$ increased the production of SREBP1c (sterol regulatory element-binding protein-1c), a transcription factor which controls the expression of fatty acid and cholesterol biosynthesis genes. ${ }^{4} \mathrm{H}_{2} \mathrm{O}_{2}$ treatment resulted in increased lipid accumulation in these cells. Interesting reports have surfaced suggesting that vascular tissues from male animals generate more OS 5 and also that cells from males are more susceptible to OS. ${ }^{6}$ In humans, treatment of disorders in which increased OS is a pathologic feature reportedly results in a greater therapeutic response in males. ${ }^{7}$

Given that lipogenesis has been associated with increased oxidative stress ${ }^{4}$, and that males appear to be more sensitive to the insults of oxidative stress $^{5,6}$, we hypothesized that fetal 
gender could affect outcomes related to the treatment of GDM. Thus, we sought to determine whether treatment of mild GDM differentially affected maternal and perinatal outcomes based on the fetal gender.

\section{Materials and Methods}

This is a secondary analysis of data collected during a randomized trial of treatment for mild $\mathrm{GDM}^{2}$ at 10 participating centers in the Eunice Kennedy Shriver National Institute of Child Health and Human Development Maternal-Fetal Medicine Units Network between October 2002 and November 2007. Institutional research board approval was obtained from each of the participating centers for the conduct of the primary study.

The details of study design, outcomes, and statistical analyses were previously published in the principal analysis of these data ${ }^{2}$. In brief, women who were between 24 and 30 weeks and 6 days at the time of $50 \mathrm{~g}$ glucose challenge test, and whose 1-hour blood glucose value was between 135 and $200 \mathrm{mg}$ per deciliter ( 7.5 to $11.1 \mathrm{mmol}$ per liter), underwent a 3-hour oral glucose tolerance test (OGTT). Mild GDM was defined, on the basis of this OGTT, using criteria proposed by the Workshop of the Fourth International conference of Gestational Diabetes Mellitus ${ }^{8}$, namely fasting blood sugar $<95 \mathrm{mg}$ per deciliter $(5.3 \mathrm{mmol}$ per liter) and two or more elevated post challenge thresholds: 1-hour, $>180 \mathrm{mg}$ per deciliter (10.0 mmol per liter); 2-hour, >155 mg per deciliter ( $8.6 \mathrm{mmol}$ per liter), and 3-hour, > 140 $\mathrm{mg}$ per deciliter ( $7.8 \mathrm{mmol}$ per liter). Exclusion criteria were: preexisting diabetes mellitus, history of stillbirth, multi-fetal pregnancy, asthma or chronic hypertension, current use of corticosteroids, known fetal anomaly, or anticipated imminent preterm delivery. Those who had no exclusion criteria, who had mild GDM, and who consented to participation were then randomly assigned by the coordinating center to nutritional counseling and $\operatorname{diet}^{9}$ with insulin use as needed (treatment group) or to routine prenatal care (control group). An additional group of women, who had a normal OGTT were also enrolled by the coordinating center into the group of women who received routine prenatal care in order to ensure that medical personnel would be unaware whether patients in the group had mild GDM. Insulin therapy was initiated if the majority of fasting or postprandial values were elevated (fasting $\geq 95 \mathrm{mg}$ per deciliter or 2-hour postprandial $\geq 120 \mathrm{mg}$ per deciliter [6.7 mmol per liter]). Random values $>160 \mathrm{mg}$ per deciliter $(8.9 \mathrm{mmol} / \mathrm{liter})$ or fasting values $\geq 95 \mathrm{mg} / \mathrm{dL}$ were used as criteria for initiating insulin in the control group. Such patients were not removed from the control group as the analysis was conducted according to the intention to treat principle.

Maternal outcomes that were assessed included hypertensive disease of pregnancy, shoulder dystocia, and cesarean delivery. Neonatal outcomes included hypoglycemia, hyperinsulinemia, ${ }^{10}$ hyperbilirubinemia, elevated cord-blood C-peptide levels, birth weight, fat mass, stillbirth or neonatal death, and birth trauma. For this secondary analysis, the outcomes were evaluated using not only raw birth weight but also centiles and z-scores based on published standard populations. ${ }^{11}$ Additionally, the effect of therapy on lean body mass, defined as birth weight minus fat mass, of the neonate was determined. Composite adverse outcomes for both the neonate (preterm birth, SGA or NICU admission) and the mother (labor induction, cesarean delivery, preeclampsia or gestational hypertension) were evaluated. Hyperinsulinemia was defined as cord blood C-peptide level $>95^{\text {th }}$ percentile 
(1.77 ng per milliliter), while hypoglycemia was defined as glucose $<35 \mathrm{mg} /$ deciliter (1.9 mmol per liter) ${ }^{10}$ Neonatal fat mass was estimated based on the technique described by Catalano et al, which ${ }^{12}$ combines measurement of chest and limb circumferences with caliper measurement of skinfold thickness to estimate subcutaneous fat mass.

The focus of this secondary analysis was whether there was an interaction between fetal gender and treatment group with regard to obstetric and perinatal outcomes. Thus, the frequencies of outcomes based on treatment status (i.e., treatment versus routine care) were stratified according to a newborn's gender. For categorical variables, the Breslow-Day test for homogeneity of the odds ratios was used to test for the presence of interactions. For continuous variables, Student's t-test was used for univariate analysis and analysis of variance (ANOVA) was used to test for the presence of interactions. Lastly, because the study groups were not balanced with regard to alcohol use, ${ }^{2}$ which was more prevalent in the treatment group, regression models were generated that estimated the interactions between fetal gender and outcome while controlling for the potentially confounding variable of alcohol use.

Statistical analyses were conducted with SAS software (SAS Institute, Cary, NC). A nominal two-sided $\mathrm{P}$ value less than 0.05 was considered to indicate statistical significance and no adjustments were made for multiple comparisons.

\section{Results}

There were a total of 469 women with male fetuses and 463 women with female fetuses in the study population who met inclusion criteria for this analysis and had delivery data available. As noted in the primary analysis ${ }^{2}$ there was no significant difference in maternal BMI on entry into the study. There were no significant interactions between fetal gender and treatment group with regard to the majority of perinatal (Table 1) or maternal (Table 2) outcomes. There were, however, significant interactions between treatment group and gender for birth weight centile ( $\mathrm{p}=0.02)$, as well as for neonatal fat mass ( $\mathrm{p}=0.04)$ (Table 1). Specifically, male offspring were significantly more likely to have both a lower birth weight centile $(50.7 \pm 29.2 \vee 62.5 \pm 30.2$ centile, $\mathrm{p}<0.0001)$ and less neonatal fat mass $(487 \pm$ 229.5 vs. $416.6 \pm 172.8 \mathrm{~g}, \mathrm{p}=0.0005$ ) whereas these differences were not significant among female offspring. Conversely, there was no significant difference in lean body mass (Table 1) which may indicate that the weight difference observed with treatment was due to the effect on fat accretion. Results were similar after adjustment for alcohol use.

There was no significant interaction between gender and treatment in the development of macrocosmic (BW > 4000g). The frequency of this outcome in treated and untreated male pregnancies were 18/244 (7.4\%) and females 10/233 (4.3\%) and 24/230 (10.4\%) respectively, $\mathrm{P}=0.87$ (Breslow Day Test for homogeneity of the odds ratio).

Inclusion of maternal BMI did not significantly affect the role of fetal gender in the newborn outcomes. 


\section{Comment}

The results of this secondary analysis from the NICHD MFMU Network suggest that there may be an interaction between fetal gender and treatment of mild GDM such that there is a significantly greater reduction, associated with treatment, in both birth weight and accumulated fat mass in males than in females. There was however no interaction with regard to lean body mass.

The cause of this apparent differential effect of treatment of women with mild GDM is not known with certainty. It is intriguing to consider whether these observations could be explained by gender differences in susceptibility to oxidative stress (OS) or in the response to interventions that mitigate OS. Markers of OS have been shown to be present in maternal, placental and newborn tissues from women with GDM, ${ }^{3}$ and OS is known to have an important role in lipogenesis and fat accumulation ${ }^{3,13}$. Moreover, there is evidence that males both are more susceptible to OS 5,6 and more likely to benefit from treatment aimed at reducing $\mathrm{OS}^{7}$. Based on these reports, we hypothesized that there would be a differential response, based on fetal gender, to treatment of mild GDM, a disorder characterized by $\mathrm{OS}^{3}$. Indeed, just such a differential response was seen with regard to birth weight and fat accretion. In contrast, we found no other significant interaction between gender and treatment with regard to other perinatal or maternal outcomes.

The finding of an apparent differential benefit for male fetuses from maternal treatment of mild GDM is interesting. Because the reduction in birth weight was noted to be due to a reduction in fat mass and not lean body mass, this difference may have additional ramifications, as neonatal fat mass has been linked to long-term health problems including impaired glucose tolerance and childhood obesity. ${ }^{13,} 14$

A limitation of the study is that this was an unplanned secondary analysis. As such, we were unable to directly measure markers of OS in maternal, placental and newborn tissues. Another potential limitation is the possibility of a type I error given the number of comparisons made. Despite these limitations, our findings are intriguing and potentially consequential. In an age of increasing interest in personalized medicine, the important differential effects of therapy and prognosis based on gender have received little attention overall and even less in perinatal medicine. The current report suggests a need for further investigation concerning the relationship of gender to neonatal and pediatric outcomes in diabetic pregnancies.

\section{Acknowledgments}

The project described was supported by grants from the Eunice Kennedy Shriver National Institute of Child Health and Human Development (NICHD) [HD27915, HD34116, HD40485, HD34208, HD27869, HD40500, HD40560, HD34136, HD40544, HD27860, HD40545, HD53097, HD21410, HD27917, HD40512, HD53118, HD36801], General Clinical Research Centers Grant [M01-RR00034] and the National Center for Research Resources [UL1RR024989, M01-RR00080, UL1-RR025764, C06-RR11234] and does not necessarily represent the official views of the NICHD or NIH.

The authors wish to thank the Subcommittee members who participated in protocol development and coordination between clinical research centers (Jo-Ann Tillinghast, R.N., M.S.N. and Francee Johnson, R.N., B.S.N.), protocol/ data management and statistical analysis (Elizabeth Thom, Ph.D.), and protocol development and oversight (Catherine Y. Spong, M.D.). 


\section{References}

1. Crowther CA, Hiller JE, Moss JR, McPhee AJ, Jeffries WS, Robinson JS, et al. Effect of treatment of gestational diabetes mellitus on pregnancy outcomes. NEMJ. 2005; 352:2477-86.

2. Landon MB, Spong CY, Thom E, Carpenter MW, Ramin SM, Casey B, et al. A multicenter, randomized trial of treatment for mild gestational diabetes. N Engl J Med. 2009; 361:1339-48. [PubMed: 19797280]

3. Biri A, Onan A, Devrim E, Babacan F, Kavutu M, Durak I. Oxidant status in maternal and cord plasma and placental tissue in gestational diabetes. Placenta. 2006; 27:327-32. [PubMed: 16338477]

4. Sekiya M, Hiraishi A, Touyama M, Sakamoto K. Oxidative stress induced lipid accumulation via SREBP1c activation in HepG2 cells. Biochemical and Biophysical Research Communications. 2008; 375:602-7. [PubMed: 18727921]

5. Brandes RF, Mugge A. Gender differences in generation of superoxide anions in the rat aorta. Life Sci. 1997; 60:391-6. [PubMed: 9031685]

6. Malorni W, Straface E, Matcerrese P, Ascione B, Cornu S, et al. Redox state and gender differences in vascular smooth muscle cells. FEBS Letters. 2008; 582:635-42. [PubMed: 18242172]

7. Suzuki T, Bramlett HM, Dietrich WD. The importance of gender on the beneficial effects of posttraumatic hypothermia. Exp Neurol. 2003; 184:1017-26. [PubMed: 14769396]

8. Metzger BE, Coustan DR. Summary and recommendation of the fourth International Workshop Conference on gestational diabetes mellitus. Diabetes Care. 1998; 21(Suppl 2):B161-7. [PubMed: 9704245]

9. American Diabetes Association. Nutrition recommendations and intervention for diet: a position statement of the American Diabetes Association. Diabetes Care. 2008; 31(Suppl 1):S61-S78. [PubMed: 18165339]

10. Corvett, RM. Hypoglycemia and hyperglycemia in the newborn. In: Polin, RA.; Fox, WW., editors. Fetal and Neonatal Physiology. Philadelphia: W.B. Saunders; 1992. p. 406

11. Gardosi J, Francis A. A customized standard to assess fetal growth in US population. Am J Obstet Gynecol. 2009; 201:25, e1-710. [PubMed: 19576371]

12. Catalano PM, Thomas AF, Avallone DA, Amini SM. Anthropomorphic estimation of body composition. Am J Obstet Gynecol. 1995; 173:1176-81. [PubMed: 7485315]

13. Silverman BL, Metzger BE, Cho NH, Loeb CA. Impaired glucose tolerance in adolescent offspring of diabetic mothers: relationship to fetal hyperinsulinism. Diabetes Care. 1995; 18:611-7. [PubMed: 8585997]

14. Hillier TA, Pedula KL, Schmidt MM, Mullen JA, Charles MA, Pettitt DJ. Childhood obesity and metabolic imprinting: the ongoing effects of maternal hyperglycemia. Diabetes Care. 2007; 30:2287-92. [PubMed: 17519427]

\section{Appendix}

In addition to the authors, other members of the Eunice Kennedy Shriver National Institute of Child Health and Human Development Maternal-Fetal Medicine Units Network are as follows:

Wayne State University - Y. Sorokin, G. Norman, P. Lockhart, S. Blackwell, L. Quast

University of Texas Southwestern Medical Center - K. Leveno, L. Moseley, J. Gold, D.

Bradford, L. Fay, M. Garcia, F. Capellan

Columbia University - M. Miodovnik, F. Malone, S. Bousleiman, H. Husami, V. Carmona, N. Fredericks, E. Gantioqui, B. Greenspan, M. Williams 
University of Utah - K. Anderson, P. Ashby, S. McAllister (University of Utah Health Sciences Center); S. Quinn, F. Castinella (LDS Hospital), A. Guzman ; J. Steiner (McKayDee Hospital), J. Parker (Utah Valley Regional Medical Center)

University of Alabama at Birmingham - J. Sheppard, J. Tisdale, A. Northen, W. Andrews

Brown University - D. Catlow, D. Allard, M. Seebeck, J. Tillinghast

The Ohio State University — J. Iams, F. Johnson, C. Latimer, E. Weinandy, B. Maselli

University of North Carolina at Chapel Hill — K. Dorman, S. Brody, S. Timlin, J.

Bernhardt

Drexel University - M. Hoffman, E. Guzman, M. Talucci, T. Grossman, C. Perez, L.

Zeghibe, P. Tabangin

Case Western Reserve University-MetroHealth Medical Center - B. Mercer, B. Stetzer, C. Milluzzi, W. Dalton, S. Pichette

Wake Forest University Health Sciences - M. Swain, P. Meis, J. White

The University of Texas Health Science Center at Houston - L. Gilstrap, K. Cannon, J.

Martinez, D. Dusek

University of Texas Medical Branch — J. Moss, J. Brandon, A. Jackson, G. Hankins, D. Sharp

University of Pittsburgh - M. Bickus, H. Birkland, M. Cotroneo, N. Cuddy

Northwestern University — P. Simon, G. Mallett

Oregon Health \& Science University — L. Davis, E. Lairson, C. Cromett, C. Naze, M.

Blaser

The George Washington University Biostatistics Center - E.Thom, J. Zachary, B.

Getachew, C. Cobb, L. Leuchtenburg, S. Gilbert

Eunice Kennedy Shriver National Institute of Child Health and Human Development - C. Spong, S. Tolivaisa, K. Howell

MFMU Network Steering Committee Chair (University of Texas Medical Branch, Galveston, TX) - G.D. Anderson, M.D.

Condensation:

The beneficial effects of treatment of mild gestational diabetes in reducing birth weight and neonatal fat mass is greater in magnitude among male fetuses. 


\begin{tabular}{|c|c|c|c|c|c|c|c|c|c|c|c|c|c|c|c|}
\hline " & $\begin{array}{l}\text { त̂ } \\
\text { on }\end{array}$ & @o & $\stackrel{\delta}{0}$ & $\stackrel{\infty}{0}$ & : & $=$ & \begin{tabular}{l}
$\infty$ \\
\multirow{0}{0}{}
\end{tabular} & $\bar{\delta}$ & : & $\stackrel{\circ}{\circ}$ & $\begin{array}{l}\bar{Z} \\
0\end{array}$ & $\underset{0}{J}$ & & 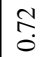 & $\mid \begin{array}{l}\infty \\
\infty \\
0\end{array}$ \\
\hline 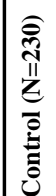 & $\begin{array}{l}\infty \\
\stackrel{+}{+1} \\
\partial_{0} \\
\infty \\
\infty\end{array}$ & 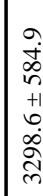 & $\begin{array}{l}\frac{m}{m} \\
+1 \\
+1 \\
\stackrel{b}{0}\end{array}$ & 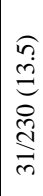 & 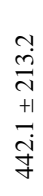 & 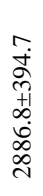 & 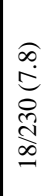 & 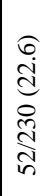 & $\begin{array}{l}\underset{\stackrel{\partial}{\Xi}}{\stackrel{D}{\leftrightarrows}} \\
\underset{\infty}{\infty}\end{array}$ & 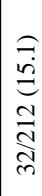 & 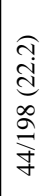 & $\begin{array}{l}\widehat{]} \\
\text { ḋ } \\
\text { dิ } \\
\text { in }\end{array}$ & & 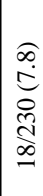 & $\begin{array}{l}n \\
n \\
0 \\
0 \\
\tilde{n} \\
\infty\end{array}$ \\
\hline
\end{tabular}




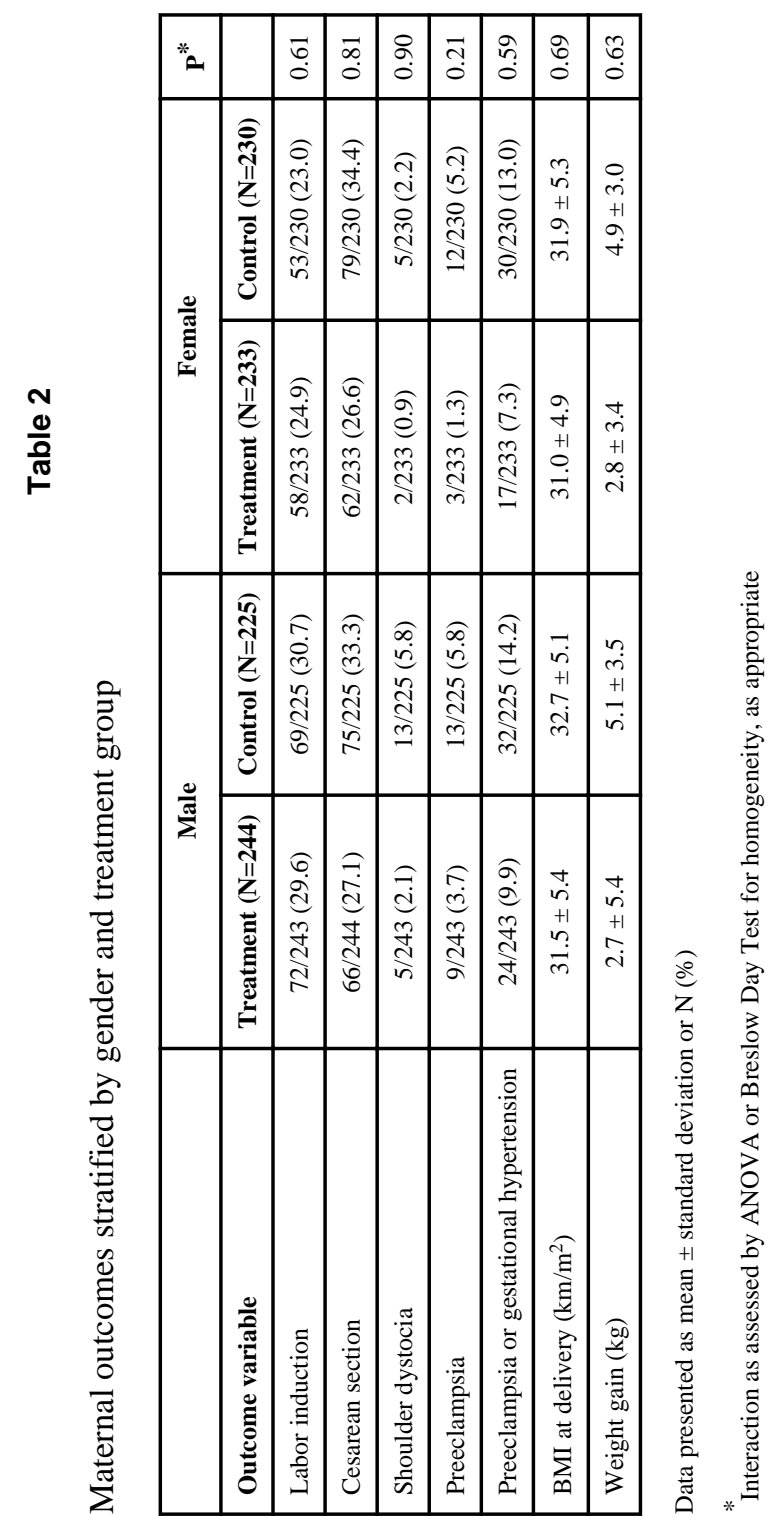

Am J Obstet Gynecol. Author manuscript; available in PMC 2014 August 26. 